\title{
ENAMEL ETCHING WITH AN ERBIUM, CHROMIUM: YTTRIUM- SCANDIUM-GALLIUM-GARNET LASER SYSTEM VERSUS COVENTIONAL ACID ETCHING TECHNIQUE IN BONDING METALLIC BRACKETS
}

\author{
Hanady M. Samih*, Khaled S. Aboul Azm*,
}

Maha M. Adly Abd El-Motie ${ }^{* * *}$

ABSTRACT:

Introduction: The purpose of this study was to compare the shear bond strength of orthodontic brackets bonded to enamel etched with Er,Cr:YSGG laser at three different power outputs versus conventional acid etch. Materials and methods: Eighty-eight human premolars extracted for orthodontic purpose were used and were randomly divided into four equal groups according to enamel conditioning method. Enamel was etched with $\mathrm{Er}, \mathrm{Cr}: \mathrm{XSGG}$ laser system operated at one of three power outputs (1.5W, 2.0W and 2.5W) and with $37 \%$ orthophosphoric acid. Metal brackets were bonded to the etched enamel of eighty teeth using Transbond Plus adhesive material. The etched enamel surfaces of two teeth from each group were examined under scanning electron microscope (SEM). The shear bond strength was measured for all the groups using universal testing machine. The amount of remaining adhesive material on the teeth surface was determined using adhesive remnant index (ARI) scored from 0 to 3.

Lecturer, Orthodontics Department, Faculty of Dentistry, Suez Canal University, Ismailia, Egypt.

** Lecturer, Orthodontics, Faculty of Dentistry, Pharos University, Alexandria, Egypt.

*** Assistant Professor, Dental Biomaterials Department, Faculty of Dentistry, Alexandria University, Alexandria, Egypt. 
Egyptian

Orthodontic Journal

Results: The means and standard deviations of shear 6ond strength for acid-etch group, 1.5W laser group, 2W laser group and $2.5 \mathcal{W}$ laser group were $9.60 \pm 0.71,7.22 \pm 0.78,11.68 \pm 0.83$ and $12.43 \pm 0.71$, respectively. The findings were confirmed by the scanning electron microscope. The evaluation of adhesive remnant index scores showed significant difference in bond failure site between all laser etched groups and acid etched group. There was more adhesive left on the enamel surface etched with acid than with laser. Conclusion: The mean shear bond strength and enamel etching with Er,Cr: YSGG laser at $2 \mathcal{W}$ power output for 20 seconds is clinically acceptable and comparable with conventional acid-etch. It can be considered as an alternative to acid-etch technique.

\section{INTRODUCTION}

In orthodontic practice, the strength of bonding and its durability are of critical importance in the efficient application of biomechanics and in realizing the full potential of any appliance. ${ }^{1}$ The strength of the bond depends on 3 factors, namely, the retention mechanism of the bracket base, the adhesive material or bonding resin, and the preparation of the tooth surface. ${ }^{2}$

Buonocore in $1955,{ }^{3}$ was the first to set the elimination of the smear layer by acid etching as the standard protocol for successful bonding. Among the various proposed methods, etching with 37\% phosphoric acid is the most widely used. The enamel acid etching has been the subject of many investigations. The major effect on enamel is the production of microporosity with irregular enamel surface (tags). ${ }^{4}$ These enamel tags were created by selectively dissolving hydroxyapatite crystals, permitting penetration of the fluid adhesive components, and this penetration provides micromechanical retention. ${ }^{5}$ Development of these micromechanical bonds contributes to long-term bonding strength. Enamel etching alters the surface from a low-energy hydrophobic surface to a high-energy hydrophilic surface and increases the surface area. ${ }^{6}$ 
Despite the fact that the acid etching method is a useful procedure in orthodontics, the loss of mineral crystals, essentially the acid protecting barrier, is inevitable. ${ }^{7}$ One potential disadvantage of acid etching is the possibility of decalcification of the most superficial layer, which increases the predisposition of enamel to dental caries critically around and under orthodontic brackets. ${ }^{8}$ Additionally, the acid etch technique involves several steps, time consuming and is technique sensitive. ${ }^{9}$

Recently, alternative methods for preparing dental hard tissues, such as laser irradiation, have been developed. ${ }^{8}$ In 1960, Maiman ${ }^{10}$ developed the method of light amplification by the stimulated emission of radiation, now commonly known by its acronym, LASER. Five years later, Goldman et al. ${ }^{11}$ investigated the application of the laser beam on dental hard tissues. Several types of lasers, such as carbon dioxide $(\mathrm{CO} 2)$ and neodymium:yttrium-aluminum-garnet (Nd:YAG) lasers, have been used in dental practice. The first commercially available lasers were suitable for soft tissue treatments, especially in periodontics. However, when these lasers were applied to dental hard tissues, the result was major thermal damage rendering these lasers unsuitable for hard tissue treatments. $^{11-13}$ The development of the erbium,chromium: yttriumscandium-gallium-garnet (Er,Cr:YSGG) laser, which has $2780 \mathrm{~nm}$ wavelenght , permit ablation in both soft and hard tissues without any thermal side effects. This lasers can ablate enamel and dentin effectively because its light is highly and efficiently absorbed by both water and hydroxyapatite as its wave lengths coincide with the main absorption peak of water and hydroxyapatite. ${ }^{12}$ Mechanism of action is by direct vaporization and micro-explosions of water entrapped within the hydroxyapetite matrix. ${ }^{14-17}$ Histological studies have revealed no pulpal inflammatory responses in dental hard tissue irradiated with the Er,Cr:YSGG laser. Additionally it has been proved that this laser has an antimicrobial effect. ${ }^{3,5}$ These characteristics make the erbium family more popular in orthodontics. ${ }^{18}$

The preference of the laser etched surface is resistance to dental caries. Laser etching of dental hard tissue changes the calcium to phosphate ratio, reduces the carbonate-to-phosphate ratio, and leads to the formation of a more stable and less acid soluble compounds, therefore, decreases the susceptibility to acid attack and caries. In addition, with laser etching, procedural errors can be reduced and time saved. ${ }^{19}$ 
Egyptian

Orthodontic Journal

After Er,Cr:YSGG laser irradiation, the surface alteration of enamel and dentine shows micro-irregularities and the absence of a smear layer. ${ }^{20}$ This suggests that the Er,Cr:YSGG laser may etch enamel suitably for orthodontic purposes. There are some studies which have evaluated the effect of laser etching on bond strength of orthodontic brackets with controversial results. Therefore, the present study was conducted to compare shear bond strength (SBS) of orthodontic brackets bonded to enamel etched with Er,Cr:YSGG laser at three different power outputs versus conventional acid-etching.

\section{MATERIALS AND METHODS}

Eighty-eight human premolars (maxillary and mandibular 1st and 2nd) that had been extracted for orthodontic purposes were used in this study. Transillumination together with binocular loupes (Riester SuperVu $\mathrm{XL}, 5.5 \mathrm{x}$ magnification, Germany) were used to examine all the teeth. Teeth with caries, restorations, cracks or enamel defects were excluded. Teeth had neither history of chemical substance application such as hydrogen peroxide nor were they previously bonded. After rinsing the teeth and removing any remaining soft tissue, the teeth were stored at room temperature in distilled water. To prevent bacterial growth, the water was changed weekly.

Eighty teeth were mounted vertically in a self-curing acrylic resin (Probase Cold, Ivoclar Vivadent Inc., Germany) cylinder so that the crown was exposed. The long axis of each tooth was aligned vertically to the base of cylinder. The buccal enamel surfaces of the teeth were cleaned with oil-free pumice for 10 seconds, washed for 30 seconds, and dried for 10 seconds with a moisture-free air spray. Then the teeth were randomly divided into four groups of 22 premolars each. The four groups were as follows:

- Group 1 - the enamel was etched with 37\% phosphoric acid for 20 seconds, washed for 30 seconds and dried for 10 seconds with moisture (oil and water) free air spray until the etched enamel showed chalky frosty appearance.

- Group 2 - Er,Cr:YSGG laser etching was done at $1.5 \mathrm{~W}$ power output for 20 seconds.

- Group 3 - Er,Cr:YSGG laser etching was done at $2 \mathrm{~W}$ power output for 20 seconds. 
- Group 4 - Er,Cr:YSGG laser etching was done at $2.5 \mathrm{~W}$ power output for 20 seconds.

The hard tissue laser device (Waterlase iPlus, Biolase Technology, Inc. \$ Cromwell, Irvine, CA 92618 USA) which operates at a wavelength of 2,780 $\mathrm{nm}$ and the Gold handpiece with the sapphire tip (MGG6, $0.6 \mathrm{~mm}$ diameter) were used (Figure 1). The average pulse repetition rate can be varied from 5 to $100 \mathrm{~Hz}$. Laser etching was performed with pulse repetition rates of 30 pulses/second $(30 \mathrm{~Hz})$. The average power output can be varied from 0.1 to $10 \mathrm{~W}$. Three power settings $(1.5 \mathrm{~W}, 2 \mathrm{~W}$, and $2.5 \mathrm{~W})$ were used. The air and water levels were $80 \%$ and $80 \%$ respectively (Figure 2 a,b,c). The laser beam was perpendicular to the enamel at a distance of nearly $1-2$ $\mathrm{mm}$ above the surface in non-contact mode and horizontal sweeping motion (Figure $2 \mathrm{~d}$ ). The area was marked before irradiation. Then the teeth were dried with moisture- free air spray until the chalky frosty appearance of enamel was visible.



Figure 1: The Waterlase iPlus (Er,Cr:YSGG) laser unit used in the study. 




Figure 2 (a, b \& c): The laser settings used for group $2,3 \& 4,(1.5 \mathrm{~W}, 2 \mathrm{~W} \& 2.5 \mathrm{~W}$ respectively). (d): The laser beam was perpendicular to the enamel at a distance of nearly 1-2 $\mathrm{mm}$ above the surface in non-contact mode.

After etching, two teeth of each group were used for examination of etched enamel surfaces under scanning electron microscope (Jeol 35 SEM, Japan).

\section{Bonding Procedure:}

Stainless steel premolar brackets (Victory series, 3MUnitek, Monrovia, CA, U.S.A) were bonded on eighty teeth (twenty teeth for each group). These brackets had a bonding area of $10.38 \mathrm{~mm}^{2}$. A thin uniform coat of Transbond XT primer (3M Unitek, Monrovia, CA, U.S.A) was applied to the etched surfaces. After the application of Transbond Plus adhesive material (3M Unitek, Monrovia, CA, U.S.A), the brackets were pressed firmly onto the tooth surface, and excessive adhesive was removed from 
Egyptian

Orthodontic Journal

the periphery of the bracket base, using a sharp scaler. Each side of the bracket (mesial, distal, occlusal and gingival) was light cured for 5 seconds using Mr Light (Dr's light, Good Doctors Co., Seoul, Korea), LED curing system, for a total of 20 seconds. The samples were stored in distilled water at room temperature till debonding. The specimens were thermocycled for 500 cycles from $5^{\circ} \mathrm{C}$ to $55^{\circ} \mathrm{C}$ with a dwell time of 30 seconds and a transfer time of 10 seconds.

\section{Evaluation of shear bond strength}

The shear bond test was accomplished with a chisel edge mounted on the upper jaw of a universal testing machine (Comten industries Inc., Florida, USA). The specimens were loaded in a vertical occluso-gingival direction at a cross head speed of $1 \mathrm{~mm} / \mathrm{min}$. The edge of the machine (blade of the machine) was placed under the occlusal wings of the bracket, at enamel interface and parallel to the long axis of the tooth. The maximum shear force necessary to debond each bracket was recorded in Newton and then converted into megapascal (MPa) by dividing the value by the surface area of the bracket base $(\mathrm{MPa}=\mathrm{N} / \mathrm{mm} 2)$.

\section{Residual adhesive}

After debonding, the bracket bases and the enamel surfaces were examined under 30x magnification using a stereomicroscope (Olympus stereomicroscope SZ II Optical Co, Tokyo, Japan) to determine the amount of residual adhesive remaining on each tooth. The adhesive remnant index (ARI), ranging from 0 to 3, was used to describe the amount of adhesive left on the enamel surfaces. A score of 0 indicates no adhesive remained on the enamel surface, 1 indicates less than half of the adhesive remained on the tooth, 2 indicates more than half of the adhesive remained on the tooth, and 3 indicates all adhesive remained on the tooth structure or all of the enamel bonding site was covered with adhesive. ${ }^{21}$

\section{STATISTICAL ANALYSIS}

Data were fed analyzed using IBM SPSS software package (SPSS for windows, version 20.0 SPSS Inc, Chicago, IL, USA). Quantitative data were described using range (minimum and maximum) mean, standard deviation and median. Comparison between the studied groups were done using the one-way analysis of variances (ANOVA) and Post 
Hoc test of Tukey (LSD) was assessed. Chi square test was performed to determine the difference in ARI between the groups Significance of the obtained results was judged at the $5 \%$ level.

\section{RESULTS}

The means and the standard deviations of the conventional acid etch group, laser group $(1.5 \mathrm{~W})$, laser group $(2 \mathrm{~W})$ and laser group $(2.5 \mathrm{~W})$ were $9.60 \pm 0.71,7.22 \pm 0.78,11.68 \pm 0.83$ and $12.43 \pm 0.71$, respectively. One-way ANOVA analysis showed significant difference between all the four groups.

Table (1): Bond strengths for all of the studied four groups.

\begin{tabular}{|l|c|c|c|c|c|}
\hline & \multicolumn{5}{|c|}{ Groups } \\
\cline { 2 - 6 } & $\begin{array}{c}\text { Acid } \\
\text { Etch. }\end{array}$ & $\begin{array}{c}\text { Laser } \\
\mathbf{1 . 5 W}\end{array}$ & $\begin{array}{c}\text { Laser } \\
\mathbf{2 . 0 W}\end{array}$ & $\begin{array}{c}\text { Laser } \\
\mathbf{2 . 5 W}\end{array}$ & Total \\
\hline Number of specimens & 20 & 20 & 20 & 20 & 80 \\
\hline Minimum bond strength & 8.56 & 5.760 & 10.00 & 11.72 & 5.760 \\
\hline Maximum bond strength & 10.87 & 8.400 & 12.88 & 13.30 & 13.30 \\
\hline Median & 9.46 & 7.45 & 11.95 & 12.43 & 10.32 \\
\hline
\end{tabular}

Table 1 presents summary of the results of bond strengths testing for 80 specimens. Bond strength with acid etching was higher than strength with Laser $1.5 \mathrm{~W}$. Laser $2.0 \mathrm{~W}$ and $2.5 \mathrm{~W}$ specimens showed higher scores than acid etching. Laser $2.5 \mathrm{~W}$ being the highest.

Table (2): Comparison between the four studied groups according to bond strength values.

\begin{tabular}{|l|c|c|c|c|c|c|}
\hline Bond Strength & $\begin{array}{c}\text { Acid } \\
\text { Etch. }\end{array}$ & $\begin{array}{c}\text { Laser } \\
\mathbf{1 . 5 W}\end{array}$ & $\begin{array}{c}\text { Laser } \\
\mathbf{2 . 0 W}\end{array}$ & $\begin{array}{c}\text { Laser } \\
\mathbf{2 . 5 W}\end{array}$ & $\mathbf{F}$ & P \\
\hline Mean & 9.60 & 7.22 & 11.68 & 12.43 & \multirow{2}{*}{$244.431^{*}$} & $<0.001^{*}$ \\
\cline { 2 - 8 } Std. Deviation & .71 & 0.78 & .83 & 0.71 & & \multirow{2}{*}{. } \\
\hline
\end{tabular}

F: $\mathrm{F}$ test (ANOVA)

*: Statistically significant at $\mathrm{p} \leq 0.05$

Table 2 shows that the variations of readings within and between groups are significant. Bond strengths for Laser $2 \mathrm{~W}$ and $2.5 \mathrm{~W}$ groups were significantly higher than acid etching group. Bonding with Laser $1.5 \mathrm{~W}$ showed lower bond strength value than that with acid etching. 


\section{Egyptian \\ Orthodontic Journal}

Table (3): Test of significance of difference between means of the studied four groups

\begin{tabular}{|ll|c|c|c|}
\hline Comparison & & Mean Difference & Std. Error & P \\
\hline Acid Etch. & Laser 1.5W & $2.38620^{*}$ & .22655 & $<0.001^{*}$ \\
& Laser 2.0W & $-2.07615^{*}$ & .22655 & $<0.001^{*}$ \\
& Laser 2.5W & $-2.83285^{*}$ & .22655 & $<0.001^{*}$ \\
\hline Laser 1.5W & Laser 2.0W & $-4.46235^{*}$ & .22655 & $<0.001^{*}$ \\
& Laser 2.5W & $-5.21905^{*}$ & .22655 & $<0.001^{*}$ \\
\hline Laser 2.0W & Laser 2.5W & -.75670 & .22655 & $=0.135$ \\
\hline
\end{tabular}

p: value for Post Hoc Test (Tuckey) for comparing between Means

*: The mean difference is significant at the .05 level

Table 3 demonstrates a real difference between acid etching and Laser applications. Mean differences between acid etching and each of the three Laser applications are highly significant $(\mathrm{P}<0.001)$. Mean difference of Laser $2.0 \mathrm{~W}$ and Laser $2.5 \mathrm{~W}$ was not significant $(\mathrm{P}=0.135)$, but difference between of each of them and Laser $1.5 \mathrm{~W}$ is significant.
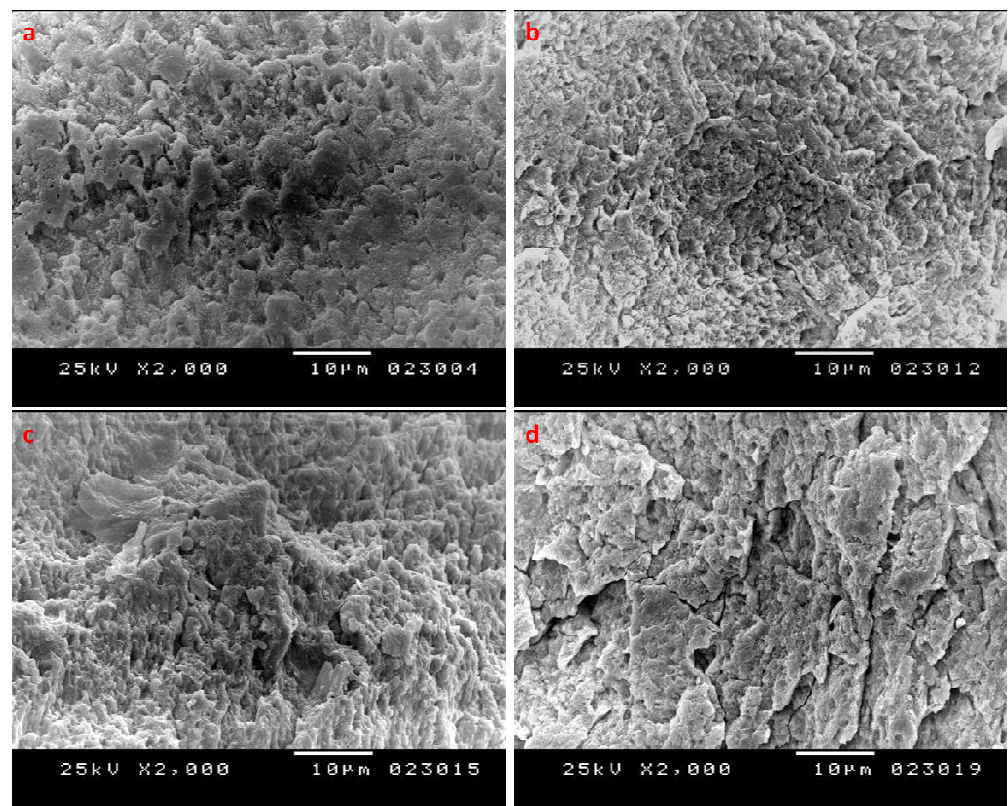

Figure 3(a): The acid-etched enamel surface. (b): Enamel surface after $1.5 \mathrm{~W}$ of Er,Cr:YSGG laser irradiation for 20 seconds. (c): Enamel surface after 2W of Er,Cr:YSGG laser irradiation for 20 seconds. (d): Enamel surface after 2.5W of Er,Cr:YSGG laser irradiation for 20 seconds.

Volume 46 - December 2014 
Egyptian

Orthodontic Journal

\section{Scanning electron microscopic examination:}

Group 1- with acid etch produced Type III enamel etched pattern with regular rough surface (Figure 3a) corresponding to a combination of Type I and Type II together according to Silverstone et $\mathrm{al}^{22}$ enamel etching patterns, where Type I showed honeycomb-like appearance because of dissolved central part (core) of enamel, leaving the prism peripheries relatively intact while Type II showed pebble-like appearance because of dissolved periphery of enamel prisms, leaving prism cores remaining relatively unaffected. The hydroxyapatite dissolved produced tags and rough surfaces that provide the mechanical lock for the adhesive material.

Group 2- with $1.5 \mathrm{~W}$ laser irradiation produced a Type I etching pattern, a honeycomb-like appearance (Figure 3b).

Group 3- with 2W laser irradiation produced a Type III etching pattern more likely similar to that produced by acid etching (Figure $3 c)$.

Group 4- with 2.5W laser irradiation produced a Type III etching pattern but with more prominent surface destruction (micro-cracks). This irradiation was much more harmful to enamel (Figure 3d).

\section{Adhesive Remnant Index (ARI) Scores}

The ARI was used to determine the bond failure site for the acid-etched group and laser-etched groups. Distribution of samples of each group according to adhesive remnant index is shown in table 4 . Ninety five percent of acid etching samples had scores 2 and 3. Laser groups had scores 1 and 0 (90\% for laser 1.5 and 2.0, 95\% for laser 2.5). The differences are significant indicating that teeth etched by laser had no or less than half of the adhesive remaining on the teeth while acid etching retained all or more than half the adhesive on the teeth. 
Table (4): Frequency distribution of Adhesive Remnant Index scores for the four different groups.

\begin{tabular}{|c|c|c|c|c|c|c|c|c|c|c|}
\hline & \multicolumn{2}{|c|}{$\begin{array}{c}\text { Acid } \\
\text { Etching } \\
(n=20)\end{array}$} & \multicolumn{2}{|c|}{$\begin{array}{c}\text { Laser } 1.5 \\
(n=20)\end{array}$} & \multicolumn{2}{|c|}{$\begin{array}{c}\text { Laser } 2.0 \\
(n=20)\end{array}$} & \multicolumn{2}{|c|}{$\begin{array}{c}\text { Laser } 2.5 \\
(\mathrm{n}=\mathbf{2 0})\end{array}$} & \multirow[t]{2}{*}{$\square^{\square}$} & \multirow[t]{2}{*}{${ }^{{ }^{M C}} \mathbf{p}$} \\
\hline & No. & $\%$ & No. & $\%$ & No. & $\%$ & No. & $\%$ & & \\
\hline \multicolumn{11}{|l|}{$\begin{array}{l}\text { Adhesive } \\
\text { Remnant Index }\end{array}$} \\
\hline 0 & 0 & 0.0 & 6 & 30.0 & 7 & 35.0 & 10 & 50.0 & \multirow{4}{*}{$52.151^{*}$} & \multirow{4}{*}{$<0.001^{*}$} \\
\hline 1 & 1 & 5.0 & 12 & 60.0 & 11 & 55.0 & 9 & 45.0 & & \\
\hline 2 & 10 & 50.0 & 2 & 10.0 & 2 & 10.0 & 1 & 5.0 & & \\
\hline 3 & 9 & 45.0 & 0 & 0.0 & 0 & 0.0 & 0 & 0.0 & & \\
\hline
\end{tabular}

$\chi^{2}$ : Chi square test,

*: Statistically significant at $\mathrm{p} \leq 0.05$

Table (5): Comparison between pairs of studied groups according to Adhesive Remnant Index scores

\begin{tabular}{|c|c|c|}
\hline \multicolumn{2}{|c|}{ Comparison } & \multirow{2}{*}{$\frac{\mathbf{P}}{<0.001^{*}}$} \\
\hline Acid Etch. & Laser $1.5 \mathrm{~W}$ & \\
\hline & Laser $2.0 \mathrm{~W}$ & $<0.001^{*}$ \\
\hline & Laser $2.5 \mathrm{~W}$ & $<0.001^{*}$ \\
\hline \multirow[t]{2}{*}{ Laser $1.5 \mathrm{~W}$} & Laser $2.0 \mathrm{~W}$ & $=0.015^{*}$ \\
\hline & Laser $2.5 \mathrm{~W}$ & $=0.024^{*}$ \\
\hline Laser $2.0 \mathrm{~W}$ & Laser $2.5 \mathrm{~W}$ & $=0.043^{*}$ \\
\hline
\end{tabular}

Sig. bet. groups was done using Chi square test

*: Statistically significant at $\mathrm{p} \leq 0.05$

Table 5 shows high significant difference between acid etch and any laser group. The significance of difference drops between laser groups being the least between laser 2.0 and laser 2.5 groups $(p=0.043)$. This difference is related to distribution within each laser group between score 0 and 1. 
Egyptian

Orthodontic Journal

\section{DISCUSSION}

Research is currently on to develop more conservative enamel conditioning systems for bracket bonding without enduring the ability to maintain clinically useful bond strength. This study was designed to evaluate whether laser (Er,Cr:YSGG) enamel conditioning can be used in orthodontics with minimal tooth structure destruction and optimal bracket retention.

Extensive researches have been carried out on the issue of bracket bonding to enamel. Phosphoric acid is considered as one of the best methods to bond resins to enamel. ${ }^{1}$ Enamel etching with phosphoric acid results in interprismatic demineralization that produces free spaces for infiltration of the adhesive, which forms around $1 \mu \mathrm{m}$ long resin tags. Yet a major disadvantage of acid etching is the demineralization of enamel which makes the enamel prone to future acid attacks and increases the risk of dental caries ${ }^{23}$, especially when plaque accumulation adjacent to the brackets aggravates the condition. ${ }^{24}$

Alternatives to phosphoric acid etching such as application of Maleic and Polyacrylic acids as well as sandblasting have been suggested, but the weak bond strength resulted from these methods lead to the limitation of their use. ${ }^{24}$ With the recent advancements in resources and materials, the Er:YAG laser has proved to be effective method to etch the enamel in short duration without compromising the shear bond strengths ${ }^{25}$. Hossain et $\mathrm{al}^{26}$ reported an increase in the calcium to phosphorus ratio, reduction of carbonate, water and organic content and pyrophosphate formation following laser etching thus, resulting in a more enamel resistance to decalcification and less susceptibility to caries attack. ${ }^{2}$ Therefore, laser irradiation might be an advantageous for etching enamel during orthodontic bonding.

The Er,Cr:YSGG laser $(2780 \mathrm{~nm})$ creates laser-energized, atomized water droplets that act as cutting particles. This laser system creates precise hard-tissue cuts by virtue of the laser energy interacting with water at the tissue interface, called a hydrokinetic theory. With this theory, not only is the temperature suppressed, but cutting efficiency is increased. $^{27}$ In this study, we used an $80 \%$ water and air rate for all

Volume 46-December 2014 
Egyptian

Orthodontic Journal

selected laser outputs. There is some controversy about the amount of water and laser efficiency. Although it was reported that the amount of water is not really important for Er,Cr:YSGG as it is for erbium: yttriumaluminum-garnet (Er:YAG) laser ${ }^{28}$, Fried et al. ${ }^{29}$ showed that the cutting efficiency is correlated with the amount of water content, as well as pulse duration. Both authors agree that, for ablation to occur, water must be present over dental surfaces, due to the higher absorption coefficient of Er,Cr:YSGG laser in water than in enamel. The usage of different power outputs causes different effects. However, lower power outputs that would probably etch enamel $(1.5 \mathrm{~W}, 2 \mathrm{~W}$, and $2.5 \mathrm{~W})$ were used in the present study.

The laser etching is painless and does not involve either vibration or heat. The ease of handling the laser apparatus prevents unnecessary etching of the enamel. ${ }^{9}$ In addition, laser application can be used in wet conditions and the water-cooled system does not cause any thermal effects on the tooth pulp. ${ }^{30}$

A laser etching time of 20 seconds was evaluated in the present study. Researchers ${ }^{5}$ reported that a laser etching time of 15 seconds was preferred because 30 seconds of laser irradiation was not useful, as shown by SEM examination. Acid-etching times can vary from 15-60 seconds. However, because reports have noted no significant differences between acid-etching times, 20 seconds of acid etching was performed. As it was not our main purpose, the required time was not recorded in this study, but it was evident that laser saves chair time, unlike acid etching, it eliminates washing the enamel surface after etching. Thus, the time needed for laser system is definitely shorter than that required for phosphoric acid. From a clinical standpoint, saving chair side time also improves adhesion because it reduces the risk of salivary contamination.

Literature reports contradictory findings concerning the use of lasers for enamel etching. Although some researchers have reported that the mean shear bond strength resulting from laser etching is lower than that from acid etching ${ }^{14,26,31,32}$, others have reported more favorable results with laser irradiation. ${ }^{33,34}$ In our study we found the highest bond strength in the $2.5 \mathrm{~W}$ laser-etched group $(12.17 \pm 0.35 \mathrm{MPa})$, followed by the $2 \mathrm{~W}$ laser-etched group $(11.68 \pm 0.83 \mathrm{MPa})$, the acid-etched group 
Egyptian

Orthodontic Journal

$(9.6 \pm 0.71 \mathrm{MPa})$ and the $1.5 \mathrm{~W}$ laser-etched group $(7.22 \pm 0.78 \mathrm{MPa})$. Maijer and $\mathrm{Smith}^{35}$ found bond strength of $8 \mathrm{MPa}$ to be adequate for orthodontic brackets. According to Reynolds, ${ }^{36}$ adequate bond forces range from 6 to $8 \mathrm{MPa}$. Our bond strength values were above these values in all laser groups and acid etch group. Thus, these etching modalities were clinically acceptable.

There was a significant difference in bond strength of all groups when compared to each other. The findings of this study were consistent with the results of previous studies, ${ }^{5,9,16,20,26,33,37,38}$ which supported the efficacy of laser etching for enamel bonding. Other studies didn't support the efficacy of laser etching. ${ }^{14,15,19,39}$ The differences in reports of previous studies either supporting or rejecting laser etching might be due to differences in emission mode, contact or non contact mode, irradiation time, water cooling, irradiation distance, power output, and pulse repetition rate. ${ }^{32}$ Morphological changes of enamel produced after laser irradiation depends on the energy density of the laser, the time of exposure, the distance of the laser tip from the surface and percentage of water irrigation. ${ }^{4}$

SEM studies ${ }^{5,19}$ have shown that enamel, after irradiation with cooled Er,Cr:YSGG laser, differs according to the energy used. In this study, the $1.5 \mathrm{~W}$ laser irradiation showed slight dissolution with small areas of porosity (Figure 3 ). The $2 \mathrm{~W}$ showed wide areas of dissolutions, numerous areas of depression and elevations with a combination of narrow and wide porosities. The $2.5 \mathrm{~W}$ showed numerous elevations and long depressions (dark areas) that appeared as micro-cracks which indicate strong micro-retentive feature. While the acid etch group revealed wide areas of dissolution with large areas of porosities (remaining enamel is elevated) with a honey-comb appearance. Hence, the SEM showed that laser irradiation of enamel at $2 \mathrm{~W}$ produced preferable etching patterns as well as the acid etched enamel while $1.5 \mathrm{~W}$ produced shallow etching pattern and $2.5 \mathrm{~W}$ produced deep destructive etching pattern.

The shear bond strength (SBS) of the $2.5 \mathrm{~W}$ laser irradiation was found to be higher than acid etching but in SEM, we noticed that there is 
Egyptian

Orthodontic Journal

deeper destruction of the enamel although we got type III etching pattern. Hence, the ideal power setting for etching the enamel to attain acceptable SBS would be of $2 \mathrm{~W}$.

In the current study, the acid etched group had the score 2-3 of ARI. These scores indicate that failure sites were mainly at the bracketadhesive interface or within the adhesive, which might suggest that more than half or all adhesive was left on the enamel surface. Most of the samples in the groups bonded with laser etching had the score 0-1 of ARI. These ARI scores clearly indicate that failure sites were mainly at the enamel-adhesive interface or within the adhesive, which might suggest that no or less adhesive was left on the enamel surface resulting in less chair time spent cleaning the teeth after debonding. ${ }^{19}$ This finding is consistent with the results of some previous studies. ${ }^{9,16,19}$ Other authors state that bond failure at the bracket-adhesive interface or within the adhesive is more desirable (safer) than failure at the adhesive-enamel interface which may lead to enamel cracks or fracture during debonding and increases the risk of enamel especially with ceramic brackets. ${ }^{24,36} \mathrm{Up}$ till now, the preferred site of failure is still a controversial and should be determined.

\section{CONCLUSIONS}

The shear bond strength and enamel surface etching obtained with Er,CR:YSGG laser at $2 \mathrm{~W}$ power output for 20 seconds, can be considered as a successful alternative to acid etching by providing higher or comparable SBS values. In spite of the advantage of laser etching, it might be outweighed by high cost of current laser units. However, with increase usage of lasers and technological advancements, the cost factor is bound to become less expensive.

\section{RECOMENDATIONS}

Further investigations are required to determine the effect of other Er,CR:YSGG laser settings on SBS, the adhesive interface and the alterations of enamel chemistry. Ability to restore the enamel surfaces to original gloss after laser etching may also be of concern and should be further evaluated. 
Egyptian

Orthodontic Journal

\section{REFERENCES}

1. Krishnan KV, Kumaran NK, Iyer VH, Rajasigamani K. Laser etched vs conventional enamel: effect on shear bond strength of orthodontic brackets. Int J Laser Dent 2013;3(1):1-6.

2. Turkoz C, Ulusoy C. Evaluation of different enamel conditioning techniques for orthodontic bonding. Korean J Orthod 2012;42(1):32-38.

3. Buonocore MG. A simple method of increasing the adhesion of acrylic filling materials to enamel surfaces. J Dent Res 1955;34:849-53.

4. Hosseini MH, Namvar F, Chalopa J, Saber K, Chiniflroush N, Sarmadi S, Mirhashemi AH. Comparison of shear bond strength of orthodontic brackets bonded to enamel prepared by Er:YAG Laser and conventional acid-etching. J Dent 2012;9(1):20-6.

5. Basaran G, Ozer T, Berk N, Hamamci O. Etching enamel for orthodontics with Erbium,Chromium:Yttrium-Scandium-GalliumGarnet laser system. Angle Orthod 2007;77(1):117-23.

6. Sagir S, Usumez A, Ademci E, Usumez S. Effect of enamel laser irradiation at different pulse settings on shear bond strength of orthodontic brackets. Angle Orthod 2013;83:973:80.

7. Kim JH, Kwon OW, Kim YH. Acid resistance of Erbium-doped Yitrium Aluminum Garnet Laser treated and Phosphoric acid etched enamels. Angle Orthod 2006;76:1052-6.

8. Basaran G, Hamaci N, Akkurt A. Shear bond strength of bonding to enamel with different laser irradiation distances. Lasers Med Sci 2011;26:146-56.

9. Ozer T, Basaran G, Berk N. Laser etching of enamel for orthodontic bonding. Am J Orthod Dentofacial Orthop 2008;134:193-7.

10. Maiman TH. Stimulated optical radiation in ruby. Nature 1960 ;187: 493-4.

11. Goldman L, Glay A, Goldman B, Meyer R. Effect of laser beam impacts on teeth. J Am Dent Assoc 1965;70:601.

Volume 46-December 2014 
12. Aoki A, Sakaki MK, Watanabe H, Ishikawa I. Lasers in non-surgical periodontal therapy. Periodont 2000;36:59-97.

13. Wigdor HA, Walsh JT, Featherstone JDB, Visuri SR, Fried D, Waldvogel JL. Lasers in dentistry. Lasers Surg Med 1995;16:103-8.

14. Von Fraunhofer JA, Allen DJ, Orbell GM. Laser etching of enamel for direct bonding. Angle Orthod 1993;63(1):73-6.

15. Martinez-Insua A, Da Silva Dominguez L, Rivera FG, Santana-Penin UA. Difference in bonding to acid-etched or Er:YAG laser treated enamel and dentin surfaces. J Prosthet Dent 2000;84(3):280-8.

16. Lee BS, Hsieh TT, Lee YL, Lan WH, Hsu YJ, Wen PH, Lin CP. Bond strengths of orthodontic bracket after acid-etched, Er:YAG laser-irradiated and combined treatment on enamel surface. Angle Orthod 2003;73(5):565-70.

17. Kim JH, Kwon OW, Kim HI, Kwon YH. Effectiveness of an Er:YAG laser in etching the enamel surface for orthodontic bracket retention. Dent Mater J 2005;24(4):596-602.

18. Korkmaz Y, Ozel E, Attar N, Bicer C.Influence of different conditioning methods on the shear bond strength of novel light-curing nano-ionomer restorative to enamel and dentin. Lasers Med Sci 2010;25(6):861-6.

19. Berk N, Basaran G, Ozer T. Comparison of sandblasting, irradiation, and conventional acid etching for orthodontic bonding of molar tubes. Eur J Orthod 2008;30:183-9.

20. Hossain M, Nakamura Y, Yamada Y, Kimura Y, Nakamura G, Matsumoto K. Ablation depths and morphological changes in human enamel and dentin after Er,Cr:YSGG laser irradiation in human enamel and dentin: ablation and morphological study. J Clin Laser Med Surg 1999(b);17:155-61.

21. Artun J, Bergland S. Clinical trials with crystal growth conditioning as an alternative to acid-etch enamel pretreatment. Am J Orthod 1984;85:333-40. 
22. Silverstone LM, Saxton CA, Dogan IL, Fjerskov D. Variation in the pattern of acid etching human dental enamel examined by scanning electron microscope. Caries Res.1975;9:373-87.

23. Hashimoto M, Ohno H, Yoshida E, Hori M, Sano H, Kaga M, Oguchi H. Enamel bonds made with self-etching primers on ground enamel. Eur J Sci 2003;111:447-53.

24. Yassaei S, Fekrazad R, Shahraki N, Moghadam MG. A comparison of shear bond strengths of metal and ceramic brackets using conventional acid etching technique and Er:YAG laser etching. J Dent Res Dent Clin Dent Prospect 2014;8(1):27-34.

25. Chimello-Sousa DT, De Souza AE, Chinelatti MA, Pecora JD, Palma-Dibb RG, Corona SA. Influence of Er:YAG laser irradiation distance on the bond strength of a restorative system to enamel. $\mathrm{J}$ Dent 2006;34:245-51.

26. Hossain M, Nakamura Y, Tamaki Y, Yamada Y, Murakami Y, Matsumoto K. Atomic analysis and knoop hardness measurement of the cavity floor prepared by Er,Cr:YSGG laser irradiation in vitro. J Oral Rehabil 2003;30:515-21.

27. Eversole LR, Rizoiu IM. Preliminery investigations on the utility of an Erbium Chromium YSGG laser. Can Dent Assoc J 1995;23:41-9.

28. Meister J, Franzen R, Forner K, Grebe H, Stanzel S, Lampert F, Apel C. Influence of the water content in dental enamel and dentin on ablation with the erbium YAG and YSGG lasers. J Biomed Opt 2006; 11:340-30.

29. Fried D, Ashouri N, Breunig T, Shori R. Mechanism of water augmentation during IR laser ablation of dental enamel. Laser Surg Med 2002;31:186-37.

30. Arora K, Shetty PC, Ramachandra CS, Laxmikanth SM, Sham NB. Alternate way of etching enamel for effective clinical management during practice. J Dent Laser 2012;2(6):46-50.

31. Usumez A, Aykent F. Bond strengths of porcelain laminate veneers to tooth surfaces prepared with acid and Er,Cr:YSGG laser etching. J Prosthet Dent 2003; 90:24-30. 
32. Cardoso MV, De Munck J, Coutinho E, Ermis RB, Van Landuyt K, De Carvalho RC, Van Meerbeek B. Influence of Er,Cr:YSGG laser treatment on microtensile bond strength of adhesives to enamel. Oper Dent 2008;33:448-55.

33. Dunn WJ, Davis JT, Bush AC. Shear bond strength and SEM evaluation of composite bonded to Er:YAG laser prepared dentin and enamel. Dent Mater 2005;21:616-24.

34. Lessa FC, Mantovani CP, Barroso JM, Chinelatti MA, Palma-Dibb RG, Pecora JD, Borsatto MC. Shear bond strength to primary enamel:influence of Er:YAG laser irradiation distance. J Dent Child 2007;74:26-9.

35. Maijer R, Smith DC. A new surface treatment for bonding. J Biomed Mater Res 1979;13:975-85.

36. Reynolds IR. A review of direct orthodontic bonding. Br J Orthod 1975;2:171-80.

37. Bishara SE, Vonwald L, Laffoon JF, Warren JJ. Effect of a self-etch primer /adhesive on the shear bond strength of orthodontic brackets. Am J Orthod Dentofacial Orthop 2001;119:621-4.

38. Kameyama A, Kato J, Aizawa K, Suemori T, Nakazawa Y, Ogata T, et al. Tensile bond strength of one step self-etch adhesives to Er:YAG laser irradiated and non-irradiated distance. Dent Mater J 2008;27:386-91.

39. Corpas-Pastor L, Villalba Moreno J, De Dios Lopez-Gonzalez Garrido J, pedraza Muriel V, Moore K, Elias A. Comparing the tensile strength of brackets adhered to laser-treated enamel and dentin surfaces. J Prosthet Dent 2000;84:280-8. 